\title{
Patient capacity for self-care in the medical record of patients with chronic conditions: a mixed-methods retrospective study
}

\author{
Kasey R Boehmer ${ }^{1 *}$ D, Maria Kyriacou², Emma Behnken ${ }^{1}$, Megan Branda ${ }^{1,3}$ and Victor M Montori ${ }^{1}$
}

\begin{abstract}
Background: Patients with chronic conditions must mobilize capacity to access and use healthcare and enact selfcare. In order for clinicians to create feasible treatment plans with patients, they must appreciate the limits and possibilities of patient capacity. This study seeks to characterize the amount, nature, and comprehensiveness of the information about patient capacity documented in the medical record.

Methods: In this mixed-methods study, we extracted notes about 6 capacity domains from the medical records of 100 patients receiving care from 15 primary care clinicians at a single practice. Using a generalized linear model to account for repeated measures across multiple encounters, we calculated the rate of documented domains per encounter per patient adjusted for appointment type and number. Following quantitative analyses, we purposefully selected records to conduct inductive content analysis.

Results: After adjusting for number of appointments and appointment type, primary care notes contained the most mentions of capacity. Physical capacity was most noted, followed by personal, emotional, social, financial, and environmental. Qualitatively, we found three documentation patterns: patients with broad capacity notes, patients with predominantly physical domain capacity notes, and patients with capacity notes mostly in domains other than physical. Records contained almost no mention of patients' environmental or financial capacity, or of how they coped with capacity limitations. Rarely, did notes ever mention how well patients interacted with their social network or what support they provided to the patient in managing their health.

Conclusion: Medical records scarcely document patient capacity. This may impair the ability of clinicians to determine how patients can handle patient work, at what point patient capacity might become overwhelmed leading to poor adherence and health outcomes, and how best to craft feasible treatment programs that patients can implement with high fidelity.
\end{abstract}

Keywords: Minimally disruptive medicine, Patient capacity, Electronic medical record, Electronic health record, Treatment burden, Treatment planning, Chronic conditions, Chronic illness, Multimorbidity

\section{Background}

Patients with chronic conditions must mobilize their abilities and resources to access and use healthcare and enact self-care [1]. Healthcare demands, in many cases, overwhelm the capacity of patients to implement treatment programs. Furthermore, the work of healthcare competes for the same limited capacity with the work of

\footnotetext{
* Correspondence: Boehmer.Kasey@mayo.edu

'Knowledge and Evaluation Research (KER) Unit, Mayo Clinic, 200 First Street

SW, Rochester, MN 55901, USA

Full list of author information is available at the end of the article
}

life (e.g., from commitments to family, community, and employment) [1]. Given that capacity is limited and that people often find more meaning in these life activities than in patient work, [2] patients end up "adhering to something else." To reduce the risk of nonadherence to healthcare, clinicians and patients must create feasible treatment plans that reflect an understanding of the role of competing demands, the overall burden of treatment, and the limited capacity patients can mobilize to routinize self-care.

(C) The Author(s). 2018 Open Access This article is distributed under the terms of the Creative Commons Attribution 4.0 International License (http://creativecommons.org/licenses/by/4.0/), which permits unrestricted use, distribution, and 
To fashion personalized treatment programs and support patient self-management, clinicians need to understand the limits and possibilities of each patient's capacity, which includes both their strengths to self-manage [3] as well as potential barriers to self-care [4]. They may have access to basic information about patient capacity in the medical record, but the extent to which information about patient capacity for self-care is available in the medical record is currently unknown. Therefore, the aim of this study was to describe the information about patient capacity extractable from the medical record, identifying its amount, nature, and comprehensiveness.

\section{Methods}

This study used a mixed methods explanatory sequential design. This type of design first analyzes quantitative data and then uses those findings to inform the scope of qualitative design and analyses (Fig. 1) [5].

\section{Ethics}

All study procedures were approved by the Mayo Clinic Institutional Review Board. Minnesota Research Authorization law allows patients to opt out of chart review for research. Patients who did not opt out were considered for inclusion.

\section{Chart selection}

Eligible patients were adults 18 years or older, had at least one chronic condition, and had seen a primary care clinician in the previous six months. We defined a chronic condition as one "that lasts 12 months or more and either limits self-care or independent living or requires ongoing medical intervention." [6] We selected six to eight charts per clinician of the most recent visits with eligible patients from the panels of all 15 primary care clinicians at a single primary care site, within a larger healthcare system, in the upper Midwest. In total, we pulled 100 charts on June 1, 2015. Because this is a sub-study of a larger project in which patients had to give written informed consent, patients who would not be able to provide such consent if approached, e.g., patients with cognitive impairment, were excluded.

\section{Chart review}

We reviewed the chart's latest appointment with the primary care clinician and all appointments in the previous six months, with any healthcare professional in which there was a conversation in which capacity information could be elicited. Visits included any visit in- or out-patient that occurred within the healthcare system, and included primary care, care coordination, behavioral health, and specialty care visits. Visits that were simply procedural, i.e., in-patient or out-patient surgical notes, were excluded. From each chart, we extracted appointment date(s), appointment type (ED, hospitalization, primary care, specialty, or other), number of capacity notes mentioned in each domain, and the word-for-word description of capacity information noted. To extract capacity information from the chart, we used a previously described set of categories for documenting patient capacity [7]: financial, environmental, physical, personal, emotional, and social domains. These domains specifically relate to patients' ability to access and use healthcare and enact self-care, rather than considering more traditional clinical characteristics. For each domain, extractors had a list of possible items that could be included in each, which were determined a priori by consensus. Items documented in the clinical notes which clearly conveyed patient capacity but were not on the list, were discussed by the three extractors and added to

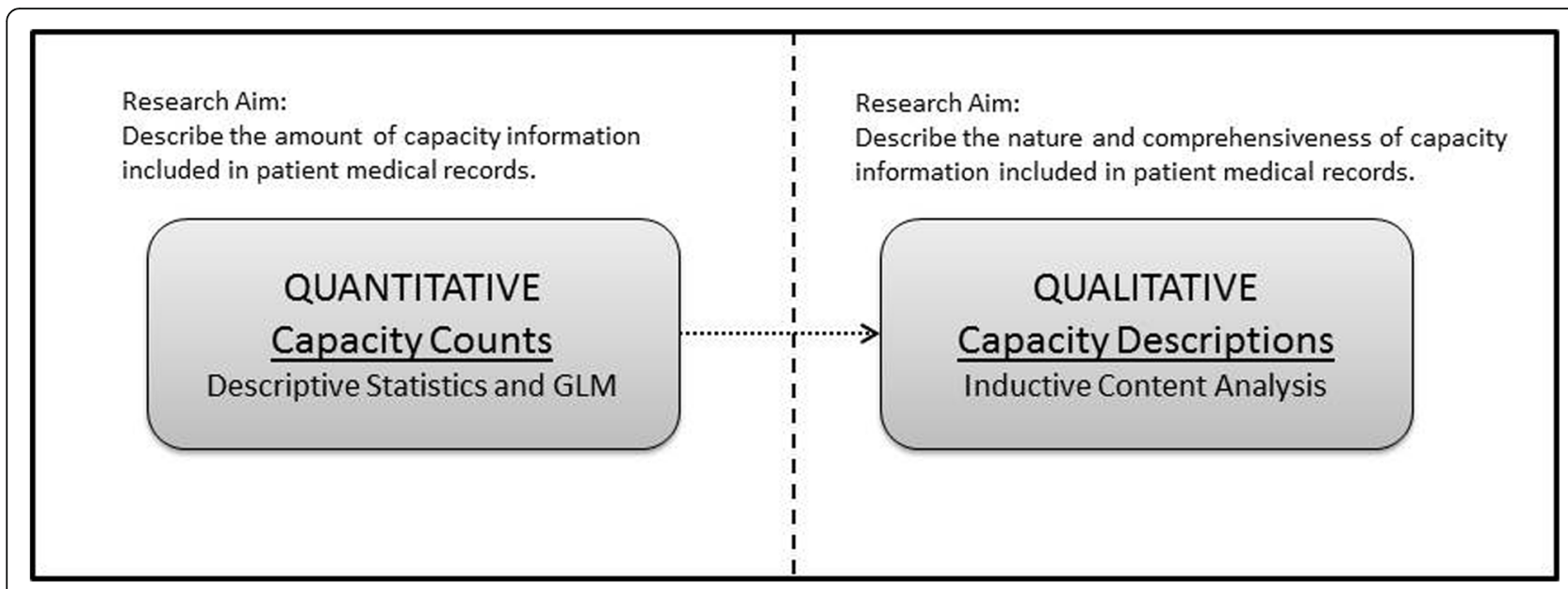

Fig. 1 Mixed Methods Explanatory Sequential Design 
the appropriate domain. Table 1 lists the items included in each domain.

$\mathrm{KB}, \mathrm{EB}$, and $\mathrm{MK}$ reviewed 10 charts in triplicate to ensure reproducible extraction, and met weekly to discuss individual extractions. We determined that after extracting the 10 charts in triplicate, good agreement was established and continued the extraction process individually until all 100 chart reviews were completed. This approach is more consistent with emergent qualitative and mixed methods designs, rather than quantitative a priori designs, which typically establish inter-rater reliability through calculation of intra-cluster correlation coefficients.

\section{Quantitative analysis}

In addition to descriptive statistics, we estimated the number of capacity notes per domain per encounter within each appointment type (i.e. all physical capacity notes within primary care appointments was summed then divided by the number of primary care appointments). This rate was then modeled using a generalized linear model to account for repeated measures across multiple encounters. The models were adjusted by appointment type and the following domains had a link of $\log$ to account for their distribution (Financial, social, environmental and emotional). The least square means with $95 \%$ CI are reported for each capacity domain by appointment type. All quantitative analyses were conducted using SAS software (SAS Institute, version 9.4).

\section{Qualitative analysis}

We purposefully selected the charts we would use for qualitative content analysis based upon the quantitative averages. We selected charts that had higher counts of capacity mentioned in any category than their unadjusted mean. We copied the text from each clinical note into NVivo qualitative data analysis software (QSR International Pty Ltd. Version 10, 2014). KB conducted inductive content analysis on all clinical notes [8]. This

Table 1 Capacity Domain Information Extracted

\begin{tabular}{ll}
\hline Physical & $\begin{array}{l}\text { Pain, Fatigue, Disability, Functioning, Conditions, } \\
\text { Symptoms, Current physical activity/exercise }\end{array}$ \\
Emotional & Anxiety, Depression, Grief, Worry, Stress, Coping \\
Social & $\begin{array}{l}\text { Relationships, Family, Friends, Caregivers (paid/unpaid), } \\
\text { Healthcare team, Volunteering, Culture, Safety in } \\
\text { Relationships }\end{array}$ \\
Personal & $\begin{array}{l}\text { Substance use, Smoking, Education, Self-Efficacy, } \\
\text { Resilience, Ability to have Conversations/Make Decisions, } \\
\text { Clinician Perceptions about Patient, Spirituality }\end{array}$ \\
Financial & $\begin{array}{l}\text { Job, Sources of Income, Financial Commitments, } \\
\text { Environmental }\end{array}$ \\
& $\begin{array}{l}\text { Financial Difficulty, Medication Costs } \\
\text { Hived Space that Affects Patient Health or Self-Care }\end{array}$ \\
\hline
\end{tabular}

process included inductive, line-by-line coding of the entire data set, and we then synthesized these codes to summarize what was learned across all notes.

\section{Results \\ Quantitative results}

Table 2 describes the sample characteristics. The patients included in the sample had a mean age of 49 (19.9) and 52\% were female. A diverse range of conditions were included in the sample. Most commonly seen conditions included type 2 diabetes, hypertension, depression, and anxiety, while less common conditions included but were not limited to irritable bowel syndrome, pain conditions, such as fibromyalgia, and asthma. The unadjusted mean of total appointments during the 6-month period was 3.4 (SD 4.0; range 1-20), with 2.1 (SD 1.7; range 1-11) of those, on average, being primary care appointments and 1.3 (SD 2.7; range 0-14) other appointment types.

Table 3 describes the unadjusted mean number of times each capacity domain was documented per patient in a 6 month period. Physical capacity was by far the most mentioned domain followed by personal, emotional, social, financial, and environmental capacity.

Table 4 shows the Least Squares Mean of capacity documentation by domain by appointment type, adjusted for number of appointments and appointment type. Primary care notes provided the most mentions of capacity across most domains, even after adjusting for number of appointments.

\section{Qualitative results}

Three patterns, i.e. patient "personas," with above average capacity notes documented emerged: patients with broad capacity notes documented, patients with predominantly physical domain capacity notes documented, and patients with capacity notes documented predominantly in domains other than the physical domain (Fig. 2).

Across all patient personas, we learned little about patients' environmental or financial capacity. For patient personas with high numbers of capacity notes documented across all domains, physical capacity notes were still most prominent, but other notes had fair representation. For patients with high numbers of capacity notes documented predominantly in the physical domain, we were able to get a good understanding of patients' conditions, symptoms, and functional limitations, but not much about their pain and fatigue. In patients with

Table 2 Sample Characteristics

\begin{tabular}{ll}
\hline Age - Mean (SD) & 48.7 (19.6) \\
Gender - \% Female & $52 \%$ \\
Number of chronic conditions - Mean (range) & $3.0(1-10)$ \\
\hline
\end{tabular}


Table 3 Times each capacity domain was mentioned per patient in 6 months of chart records ${ }^{a}$

\begin{tabular}{llll}
\hline Capacity Domain & All notes & Primary care notes only & All other notes \\
\hline Physical & $14.0(21.9), 8(4,15), 159$ & $9.5(10.9), 6(3,12), 72$ & $4.6(12.5), 0(0,3.5), 87$ \\
Personal & $5.7(6.5), 4(2,6), 31$ & $4.0(3.6), 3(2,5), 25$ & $1.8(4.1), 0(0,2), 21$ \\
Emotional & $3.1(5.9), 1(0,4), 47$ & $2.2(3.0), 1(0,3), 17$ & $0.9(3.7), 0(0,0), 30$ \\
Social & $2.6(4.3), 2(1,3), 30$ & $1.8(1.9), 1.0(0,3), 12$ & $0.8(2.9), 0(0,0), 18$ \\
Financial & $0.9(1.5), 1(0,1), 11$ & $0.7(0.8), 1.0(0,1), 4$ & $0.3(0.9), 0(0,0), 7$ \\
Environmental & $0.5(1.0), 0(0,1), 6$ & $0.3(0.6), 0(0,0), 3$ & $0.2(0.7), 0(0,0), 5$ \\
\hline
\end{tabular}

${ }^{a}$ Mean (Standard Deviation), Median (Inter-Quartile Range), Maximum

above average capacity notes documented predominantly in domains other than physical capacity, documentation of emotional capacity problems dominated the record, particularly related to depression and anxiety, as well as occasional documentation of social situations that exacerbated these problems. Across all three personas, financial capacity was barely mentioned, mostly to note employment and the way in which patients earned or received income. Only two charts subjected to content analysis mentioned cost of care or financial difficulty. Personal capacity documentation did not refer to patients' resilience or other personal capacity sources, but rather to patients' ability to understand the plan of care. Social capacity had few mentions per patient, mainly to note the existence of family members or friends. Rarely, did notes ever mention how well patients interacted with their social network or what support these people provided to the patient in managing their health. Across all personas, we also had little information about patients' abilities to cope with capacity limitations.

\section{Discussion}

This study highlights the paucity of important capacity information documented in patient medical records. To the extent that lack of documentation reflects lack of awareness of the limits and possibilities of each patient's capacity, medical record silence on capacity impedes clinicians' ability to determine how patients can handle patient work, at what point patient capacity might become overwhelmed leading to poor adherence and health

Table 4 Adjusted times capacity domain mentioned per patient, $\operatorname{LSM}(\mathrm{Cl})^{*}$

\begin{tabular}{llll}
\hline Capacity Domain & Primary care notes & All other notes & $p$ value \\
\hline Physical & $4.8(4.2-5.4)$ & $3.1(2.4-3.7)$ & $<.0001$ \\
Personal & $2.1(1.9-2.3)$ & $1.3(0.9-1.6)$ & 0.0001 \\
Emotional $^{\wedge}$ & $1.1(0.9-1.4)$ & $0.7(0.4-1.2)$ & 0.08 \\
Social $^{\wedge}$ & $1.1(0.9-1.3)$ & $0.5(0.3-0.9)$ & 0.02 \\
Financial $^{\wedge}$ & $0.41(0.33-0.50)$ & $0.15(0.09-0.27)$ & 0.001 \\
Environmental $^{\wedge}$ & $0.22(0.14-0.34)$ & $0.14(0.06-0.34)$ & 0.37 \\
\hline
\end{tabular}

${ }^{*} \mathrm{Cl}, 95 \%$ confidence interval, LSM, least square means; $\wedge$ Outcome does not follow a normal distribution therefore a log link is used outcomes, and how best to craft feasible treatment programs that patients can implement with high fidelity. The medical record is particularly silent when it comes to capacity domains associated with the most disruption by illness and treatments, as uncovered in a previous survey study of patients with chronic disease: emotional capacity, physical capacity, primarily pain and fatigue, and financial capacity [2].

Given the nature of this review, it is impossible to know if the limited mention of capacity domains reflects lack of challenges in patient lives, limited assessment and discussion during clinic visits, or limitations of the documented record. This prompts the need for more in-depth conversation analysis of encounters [9] as well as testing of interventions likely to give light to these issues during consultations [10]. Given the importance of these capacity elements to patients' ability to cope with the burden of treatment and burden of illness, careful assessment of patient capacity is necessary, with sufficient documentation to enable patient-centered team-based care.

The underwhelming documentation of capacity notes in patients with chronic conditions is particularly silent in two areas central to the work of adapting to and managing chronic disease. Both the Burden of Treatment Theory and the Theory of Patient Capacity focus on the importance of patients' social networks in coping with illness and treatment $[11,12]$. Furthermore, the Theory of Patient Capacity, as well as previous work in the experience of chronic illness, highlights the importance of patients' biography - their personal story and the extent to which it has been disrupted by their illness $[11,13,14]$. These areas received little to no mention in the notes examined.

The findings of this study cannot be considered fully without discussing its limitations. Key study limitations include: the single-site nature of the study, convenience sampling, the extraction process, and the novelty of the extraction criteria. A single primary care clinic within a large interconnected healthcare system was chosen to undertake this study due to its inclusion as a primary site for recruitment in a subsequent prospective study to test a conversation aid intended to elicit capacity 


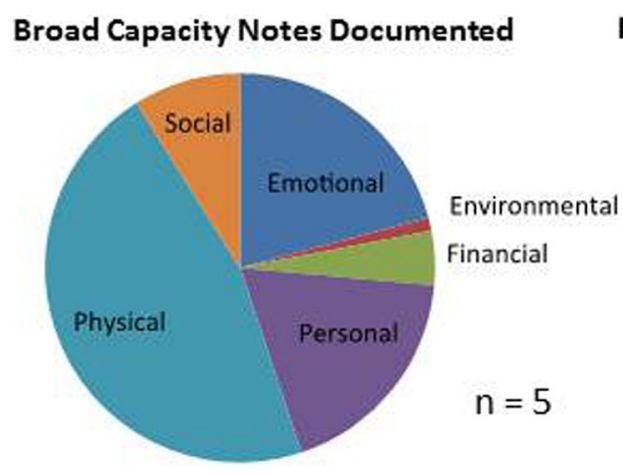

\section{Predominantly Non-Physical Capacity Notes Documented}
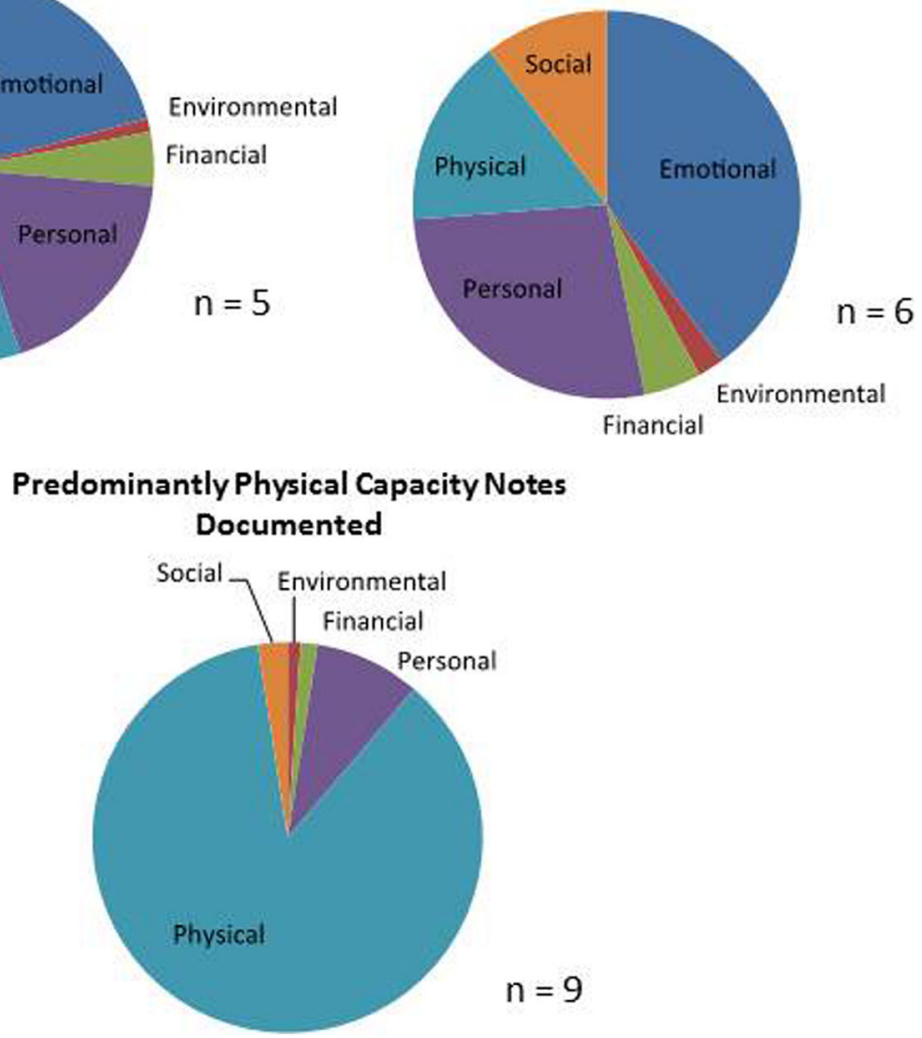

Fig. 2 Patient Personas Represented by Capacity Documentation

information during consultations. While this was a pragmatic choice, it limits the generalizability beyond similar primary care centers in the Midwest and does not necessarily transfer directly to health systems using other medical record systems. Patients included in this study were on clinicians' panels for this individual site. However, we included all notes during the six-month time period regardless of location of care within the health system, and therefore, notes included hospital, specialty, and primary care received at other clinic locations as well. Second, we selected patients consecutively based upon appointment date, a convenience sample and pragmatic choice, but one which could potentially bias results given that it was not random. Next, we took steps to reduce bias as we extracted data from charts, including conducting the first set in triplicate and meeting regularly during the extraction period. While this is typical of the study design used, other more quantitatively-oriented approaches might consider the study stronger if it would have established inter-rater reliability through calculation of intra-cluster correlation coefficients. Finally, the extraction of capacity domains is novel and has not previously been undertaken. Since the time of this analysis, a more robust
Theory of Patient Capacity [11] has been proposed and may warrant similar research using the theory. We have highlighted the key differences in the model used and recent theory in Table 5.

However, despite these limitations, this study has numerous strengths, including its explanatory sequential design. This type of design is the most appropriate for studies in which the research aims seek to explain quantitative findings. Conducting the qualitative analysis after the quantitative analysis is complete allows emergent exploration, where the second phase can be designed to explore the interesting qualitative portions of the data [5]. Therefore, other mixed methods designs, such as a convergent design where qualitative and quantitative analyses are conducted simultaneously would have been weaker for this study's research aims. Furthermore, purely quantitative description of the number of times capacity was mentioned would have been less desirable.

Furthermore, this study is the first to our knowledge that explores capacity descriptions in the medical record and may prompt additional research in other settings. Much of what is captured by documenting patient capacity entails what is often named 
Table 5 Overlap and differences between capacity domains used and more recent Theory of Patient Capacity

\begin{tabular}{|c|c|c|}
\hline $\begin{array}{l}\text { Theory of Patient Capacity } \\
\text { Constructs }\end{array}$ & $\begin{array}{l}\text { Capacity Domains Model } \\
\text { Used }\end{array}$ & Differences \\
\hline Biography & $\begin{array}{l}\text { Personal } \\
\text { Emotional }\end{array}$ & $\begin{array}{l}\text { The theory describes the importance of a successful reframing of the patient's } \\
\text { biography to include one's condition and self-care. The theory describes that } \\
\text { it is not specifically the existence of capacity in these domains, but how they } \\
\text { contribute to the overall life of the patient and their ability to pursue their life's } \\
\text { hopes, dreams, and purpose. }\end{array}$ \\
\hline Resources & $\begin{array}{l}\text { Financial } \\
\text { Physical }\end{array}$ & $\begin{array}{l}\text { The theory highlights that it is not simply the presence or absence of resources, } \\
\text { but that these resources also must be mobilized by patients. Resources captured } \\
\text { in the theory are also more encompassing beyond not just financial or physical } \\
\text { ones, but include those such as literacy and self-efficacy. }\end{array}$ \\
\hline Environment & Environmental & $\begin{array}{l}\text { The theory highlights the significant contribution of patients' healthcare } \\
\text { environment to their capacity, rather than considering purely home and } \\
\text { neighborhood environment characteristics. }\end{array}$ \\
\hline Work & & $\begin{array}{l}\text { This capacity construct is missing from the model used in this manuscript, and } \\
\text { it highlights the contribution of experiential learning from patient work that can } \\
\text { be accomplished, rather than patient work that is overwhelming, to patients' } \\
\text { capacity. }\end{array}$ \\
\hline Social & Social & $\begin{array}{l}\text { The theory expands upon the social capacity domain by highlighting it is not } \\
\text { only the existence of social support in a patient's life, but that patients are able } \\
\text { to rely on productive, rather than detrimental, relationships in their social network } \\
\text { for emotional and practical support in caring for their conditions. }\end{array}$ \\
\hline
\end{tabular}

as social determinants of health. Recently, there have been calls for, expert committee guidance on, conceptual frameworks proposed, and case studies examined of how these social determinants might come to light in and be of importance to the future of medical records [15-17]. Additionally, the practice of geriatrics has been concerned with many of these capacity issue, particularly related to environment, cognition, and physical function in the measurement and documentation of frailty [18, 19]. Ultimately, what our study points to in light of these other bodies of work is that progress is needed for the benefit of patients and the care teams that support them to ensure they are able to fashion care that fits patients' lives.

\section{Conclusion}

This study explored the extent to which patient capacity for self-care is documented in the medical record. While mentions of patient capacity appear mostly in primary care notes, the extent is limited, mostly refers to physical capacity concerns (symptoms and functional limitations), with minimal to no mention of the state of other sources of capacity. There is significant room for improving the extent and type of capacity information documented in patient records, and the meaningful conversations and careful assessments with patients these notes should reflect, to improve patient-centered care and to implement minimally disruptive medicine [20].

\section{Funding}

No external funding was received for this project.

\section{Availability of data and materials}

The datasets used and/or analysed during the current study are available from the corresponding author on reasonable request.

\section{Authors' contributions}

$\mathrm{KB}$ conceptualized and oversaw the conduct of the study with mentorship from VM. EB, KB, and MK conducted all data extraction from charts. $K B$ and $M B$ conducted the analyses. KB drafted the manuscript, and all authors provided critical revisions to the manuscript. All authors read and approved the final version of the manuscript.

\section{Ethics approval and consent to participate}

All procedures were approved by the Mayo Clinic Institutional Review Board (\#14-008621). Minnesota Chart review law allows chart review for research purposes on all patient charts without further consent procedures, unless patients opt out. Otherwise eligible patients that opted out of research chart review were not included in this study.

\section{Consent for publication}

No identifiable information is published.

\section{Competing interests}

The authors declare that they have no competing interests.

\section{Publisher's Note}

Springer Nature remains neutral with regard to jurisdictional claims in published maps and institutional affiliations.

\section{Author details}

${ }^{1}$ Knowledge and Evaluation Research (KER) Unit, Mayo Clinic, 200 First Street SW, Rochester, MN 55901, USA. ²Phoebe Family Medicine Residency, Albany, GA, USA. ${ }^{3}$ Health Sciences Research, Mayo Clinic, Rochester, MN, USA.

Received: 2 June 2017 Accepted: 24 September 2018

Published online: 02 October 2018

\section{References}

1. Shippee ND, Shah ND, May CR, Mair FS, Montori VM. Cumulative complexity: a functional, patient-centered model of patient complexity can improve research and practice. J Clin Epidemiol. 2012;65(10):1041-51.

2. Boehmer KR, Shippee ND, Beebe TJ, Montori VM. Pursuing Minimally Disruptive Medicine: Correlation of patient capacity with disruption from illness and healthcare-related demands. J Clin Epidemiol. 2016.

3. Monsen KA, Holland DE, Fung-Houger PW, Vanderboom CE. Seeing the whole person: feasibility of using the Omaha system to describe strengths of older adults with chronic illness. Res Theory Nurs Pract. 2014;28(4):299-315. 
4. Bayliss EA, Steiner JF, Fernald DH, Crane LA, Main DS. Descriptions of barriers to self-care by persons with comorbid chronic diseases. Ann Fam Med. 2003;1 (1):15-21.

5. Creswell JW, Clark VLP. Designing and conducting mixed methods research. In: SAGE; 2011.

6. AHRQ. AHRQ Announces the Release of the Chronic Conditions Indicator (CCl) for Fiscal Year 2012 (November 2011). 2011; https://www.hcup-us.ahrq. gov/news/announcements/CCl_1111.jsp. Accessed February 2017, 2018.

7. Leppin AL. Montori VM. Extending the Applicability of Clinical Practice Guidelines to Patients with Multiple Chronic Conditions. http:// minimallydisruptivemedicine.org/2018/09/28/extending-the-applicability-ofclinical-practice-guidelines-to-patients-with-multiple-chronic-conditions/.

8. Hsieh HF, Shannon SE. Three approaches to qualitative content analysis. Qual Health Res. 2005;15(9):1277-88.

9. Barry CA, Stevenson FA, Britten N, Barber N, Bradley CP. Giving voice to the lifeworld. More humane, more effective medical care? A qualitative study of doctor-patient communication in general practice. Soc Sci Med. 2001;53(4): 487-505.

10. Boehmer KR, Hargraves IG, Allen SV, Matthews MR, Maher C, Montori VM. Meaningful conversations in living with and treating chronic conditions: development of the ICAN discussion aid. BMC Health Serv Res. 2016.

11. Boehmer KR, Gionfriddo MR, Rodriguez-Gutierrez R, et al. Patient capacity and constraints in the experience of chronic disease: a qualitative systematic review and thematic synthesis. BMC Fam Pract. 2016;17(1):127.

12. May CR, Eton DT, Boehmer K, et al. Rethinking the patient: using burden of treatment theory to understand the changing dynamics of illness. BMC Health Serv Res. 2014;14:281.

13. Bury M. Chronic illness as biographical disruption. Sociology of health \& illness. 1982;4(2):167-82.

14. Charmaz K. The body, identity, and self. Sociol Q. 1995;36(4):657-80.

15. Adler NE, Stead WW. Patients in context-EHR capture of social and behavioral determinants of health. N Engl J Med. 2015;372(8):698-701.

16. DeVoe JE, Bazemore AW, Cottrell EK, et al. Perspectives in primary care: a conceptual framework and path for integrating social determinants of health into primary care practice. Ann Fam Med. 2016;14:104-8.

17. Gottlieb LM, Tirozzi KJ, Manchanda R, Burns AR, Sandel MT. Moving electronic medical records upstream. Am J Prev Med. 48(2):215-8.

18. Clegg A, Bates C, Young J, et al. Development and validation of an electronic frailty index using routine primary care electronic health record data. Age Ageing. 2016;45(3):353-60.

19. Clegg A, Young J, lliffe S, Rikkert MO, Rockwood K. Frailty in elderly people. Lancet. 381(9868):752-62

20. May C, Montori VM, Mair FS. We need minimally disruptive medicine. BMJ. 2009:339:b2803.

Ready to submit your research? Choose BMC and benefit from:

- fast, convenient online submission

- thorough peer review by experienced researchers in your field

- rapid publication on acceptance

- support for research data, including large and complex data types

- gold Open Access which fosters wider collaboration and increased citations

- maximum visibility for your research: over $100 \mathrm{M}$ website views per year

At BMC, research is always in progress.

Learn more biomedcentral.com/submissions 